\title{
GUIDE TO AUTHORS
}

Please follow these guidelines so that your manuscript may be handled expeditiously.

Nature is an international journal covering all the sciences. Contributors should therefore bear in mind those readers for whom English is a second language and those who work in other fields. Please write clearly and simply, avoiding unnecessary technical terminology. Nature's staff will edit manuscripts to those ends if necessary. Contributors should check their proofs carefully.

Because of the competition for space, many of the papers submitted for publication cannot be accepted. For this reason, and because brevity is a great assistance to readers, papers should be as brief as is consistent with intelligibility. Please note that one printed page of Nature, without diagrams or other interruptions of the text, has fewer than 1,300 words.

\section{CATEGORIES OF PAPER}

Review Articles survey recent developments in a field. Most are commissioned, but suggestions are welcome in the form of a one-page synopsis addressed to the Reviews Coordinator. Length is negotiable in advance but must not exceed six pages of Nature.

Articles are research reports whose conclusions are of general interest and which are sufficiently rounded to be a substantial advance in understanding. They should not have more than 3,000 words of text or more than six display items (figures and tables) and should not occupy more than five pages of Nature.

Articles should be accompanied by a heading of $50-80$ words written to advertise their contents in general terms, to which editors will pay particular attention. A heading (printed in italic type) is not an abstract and should not usually contain numbers or measurements. The study should be introduced in more detail in the first two or three paragraphs, which should also briefly summarize its results and implications.

Articles may contain a few subheadings of two or three words. The meaning of the text should not depend on the subheadings, whose function is to break up the text and to point to what follows. There should be fewer than 50 references

Letters to Nature are short reports of outstanding novel findings whose implications are general and important enough to be of interest to those outside the field. Letters should not have more than 1,000 words of text or more than four display items and should not occupy more than two pages of Nature. The first paragraph should describe, in not more than 150 words, the origins and chief conclusions of the study. Letters should not have subheadings or more than 30 references.

Commentary articles deal with issues in, or arising from, research that are also of interest to readers outside research. Some are commissioned, most are unsolicited. They are normally between one and four pages of Nature in length.

News and Views articles are intended to inform nonspecialist readers about a recently published advance. Suggestions should be made to the News and Views Editor. Illustrations are welcome. Proposals for meeting reports should be agreed in advance.

Scientific Correspondence is for the discussion of scientific matters, including contributions published in Nature. Priority is given to contributions of less than 500 words and five references. Figures are welcome.

\section{GENERAL}

All contributions submitted for publication in Nature should conform with these rules.

Manuscripts should be typed, double-spaced, with a good-quality printer, on one side of the paper only. Four copies are required, each accompanied by lettered artwork. Four copies of half-tones should be included. Reference lists, figure legends and so on should be on separate sheets, all of which should be double-spaced and numbered. Copies of relevant manuscripts in press or submitted for publication elsewhere should be included, clearly marked as such. Revised and resubmitted manuscripts should also be clearly marked as such and labelled with their reference numbers.

Titles should say what the paper is about with the minimum of technical terminology and in fewer than 80 characters. Authors should avoid active verbs, numerical values, abbreviations and punctuation and should include one or two key words for indexing purposes.

Artwork should be marked individually and clearly with the author's name, figure number and, when known, manuscript reference number. Original artwork should be unlettered. Ideally, no figure should be larger than 28 by $22 \mathrm{~cm}$. Figures with several parts are permitted only if the parts are closely related, either experimentally or logically. Suggestions for cover illustrations, with captions, are welcome. Original artwork (and one copy of the manuscript) will be returned when a manuscript cannot be published.

Colour Artwork. A charge of $£ 500$ a page is made for 4 colour figures. Inability to meet these costs will not prevent the publication of essential colour figures if the circumstances are explained.

Figure legends must not exceed 300 words and ideally should be much shorter, and should use telegraphic form wherever possible. The figure should be described first, then, briefly, the method. Reference to a method described elsewhere is preferable to a full description. Methods should not be described in detail in the text.

References should be numbered sequentially as they appear in the text, followed by those in tables and finally those in the figure legends. Reference numbers apply only to papers published or in the press, and a different number should be given to each paper cited. All other forms of reference (including unrefereed abstracts) should be included in the text as personal communication, manuscript in preparation or preprint (with number and institution where appropriate). Text should not be included in the reference list. References should be abbreviated according to the World List of Scientific Periodicals (fourth edition, Butterworth, London, 1963-65). The first and last page numbers should be cited. Reference to books should clearly indicate the publisher and the date and place of publication.

Abbreviations, symbols, units and Greek letters should be identified the first time they are used. Acronyms should be avoided as much as possible and, when used, defined. Editors will shorten words if necessary. In case of doubt, SI units should be used.

Footnotes should not be used except for changed addresses or to identify the corresponding author if different from the first-named.

Acknowledgements should be brief. Grant numbers and contribution numbers are not allowed.

Submission. All manuscripts may be submitted to either London or Washington. They should not be addressed to editors by name. Manuscripts or proofs sent by air courier to London should be declared as 'manuscripts' and 'value \$5' to prevent the imposition of import duty and value-added tax (VAT). 